\title{
esso
}

\section{Teachers as creators of social contexts for scientific learning New approaches for teacher education}

\author{
Ana M. Morais \\ Isabel P. Neves \\ Department of Education \& Centre for Educational Research \\ School of Science University of Lisbon
}

Article published in:

R. Moore, M. Arnot, J. Beck \& H. Daniels (Orgs.), Knowledge, Power and Educational Reform: Applying the sociology of Basil Bernstein. London: Routledge (2006).

Routledge homepage: http://www.routledge.com/ 


\title{
9 Teachers as creators of social contexts for scientific learning
}

\author{
New approaches for teacher education
}

\author{
Ana M. Morais and Isabel P. Neves
}

The increasing attention now being paid internationally to professional development reflects the need for teachers with a sound scientific and pedagogical background who are also able to implement teaching-learning processes that take into account the sociocultural diversity that is part of our schools. Wilson and Berne (1999) believe that there is progress towards achieving a consensus about the aims of teacher education. However, what we know about teachers' learning remains fragmented and disconnected. Many teacher education activities contain an evaluation process (mostly focused on what teachers have enjoyed), but efforts to measure what teachers learn and its relation to change in their pedagogic practice have not been part of typical evaluations. What the knowledges are that teachers acquire through these activities and how they influence their practice are questions that still demand an answer.

On the basis of recent research, some (e.g. Driel et al. 2001) have suggested that there are radically distinct conceptions of teachers' knowledge and that teachers' performance requires a clear definition of relevant concepts. We believe that a fundamental aspect that should be present in all teacher education is a sound evaluation of performance in order to promote professional growth. This implies the development of instruments of analysis designed to explore, in precise and detailed ways, the reasons for teachers' difficulties in planning and implementing pedagogic practices that promote effective learning by all their students.

The present study is based on research into teacher education by the ESSA Group (Sociological Studies of the Classroom) (e.g. Rocha and Morais 2000; Rosa 2002; Morais et al. 2005). Bernstein's (1990) theory of pedagogic discourse provided the main conceptual framework. The concept of specific coding orientation (recognition and realization rules) was used to evaluate the professional development of teachers in in-service training programmes using an action-research approach. The aim of this chapter is to present work on teachers' professional performance and development, in terms of specific coding orientations in relation to contexts of pedagogic intervention. We discuss the meaning of that relation and the potentialities and limitations of the methodological instruments which have been used. 


\section{Teacher performance and specific coding orientation}

We started from the idea that, as student performance in specific learning contexts presupposes a given coding orientation to these contexts, teachers' performance in specific teaching contexts also presupposes a given coding orientation to these contexts. It is, then, possible to use the same kind of conceptualization that has been used in the analysis of students' learning in the analysis of teacher performance. The assumption is that teachers' pedagogic practices may be analysed as texts (instructional and regulative) and that these texts may represent various levels of teacher performance; that is, various levels of specific coding orientation to the implementation of pedagogic practices with given sociological characteristics. The external language of description which has been developed at the micro level is then transferred to the meso level of the educational system.

For Bernstein, the acquisition of a specific coding orientation, that is the acquisition of recognition and (active and passive) realization rules for a given context, is fundamental to the success of acquirers in that context. However, Bernstein argues that for the subject to produce the legitimate text in a given context, s/he should also have the socio-affective dispositions favourable to that context: the aspirations, motivations, values and attitudes adequate to the production of that text (Figure 9.1).

According to the model, having a specific coding orientation to a given pedagogic practice means that teachers possess:

(a) recognition rules which allow the recognition of the specificity of the context of that pedagogic practice, in its multiple aspects, distinguishing it from other contexts of pedagogic practice;

(b) passive realization rules which allow the selection of meanings/justifications appropriate to that context of pedagogic practice;

(c) active realization rules which allow the production of the text required by implementing in the classroom a pedagogic practice with the proposed characteristics.

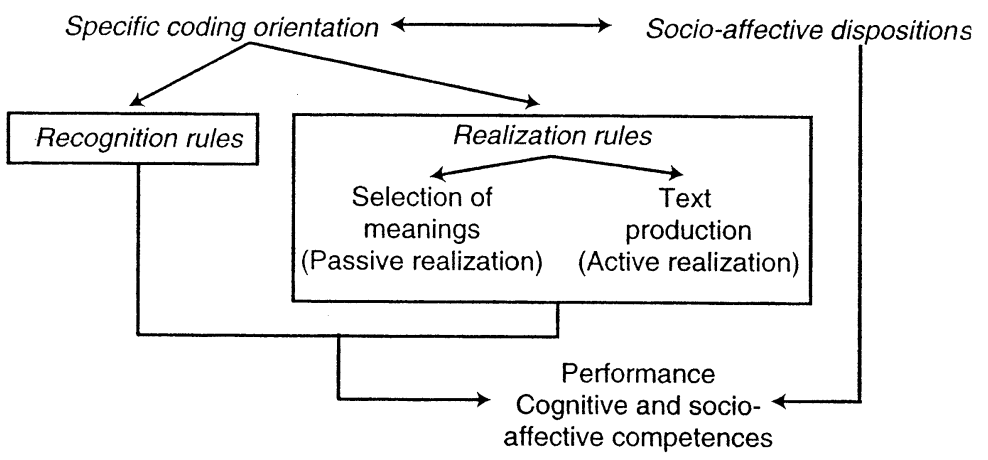

Figure 9.1 Specific coding orientation, socio-affective dispositions and performance in specific learning contexts (Morais and Neves, 2001) 
According to Bernstein's model of pedagogic discourse, since any pedagogic practice may be characterized in terms of the various social relations (between subjects, discourses and spaces) which define its instructional and regulative dimensions, teacher performance may have different levels according to the specific coding orientation to each one of these dimensions and relations. This means that the possession of recognition and realization rules (both passive and active) should not be evaluated in terms of the global context of the pedagogic practice, but rather in terms of each of the social relations which characterize its instructional and regulative dimensions.

The differentiation that is usually made between what teachers think and what teachers do may, in our model, be seen in sociological terms as having a broader meaning and higher conceptual and discriminative power. First, the ideas/representations may be distinguished by taking as analytical components those ideas teachers have about the characteristics of the pedagogic practice which may be more favourable to the learning of all students (recognition rules) and, also, the ideas they have about how these characteristics can be met and the pedagogic principles in which they are grounded (passive realization rules). Second, at the level of practice, a further distinction is possible by taking as components of analysis the instructional and regulative contexts of the pedagogic practice and, within each context, the multiple social relations which define that context. When directed to these various aspects of the pedagogic practice, the active realization represents a deeper and more subtle analysis of distinct teacher practice in the classroom.

Furthermore, the fact that the analysis of the various rules (recognition rules and passive and active realization rules) is centred on the same social relations and the fact that the same concepts (classification and framing) are used to analyse these relations, allows better, theoretically grounded and more conceptually consistent, comparisons between what teachers think and what teachers do. Figure 9.2 shows these relations.

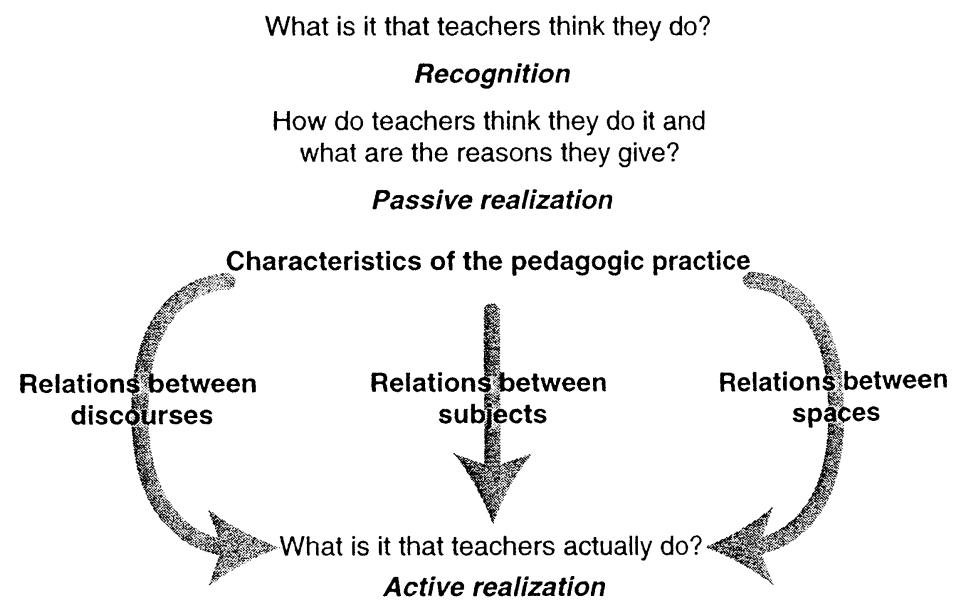

Figure 9.2 Teacher pedagogic practice - specific coding orientation 
In a study of physics and chemistry teachers of eighth and ninth grades (14-15 year olds) (Matos and Morais, 2004), we used the concepts of classification and framing to develop a comparative analysis of, respectively, the ideas and the practices of teachers when conducting experimental work in the classroom. The practices were analysed using an instrument which characterized the modalities of pedagogic practice; the ideas were analysed through interviews which had, as a starting point, the actual classroom occurrences. In this way, it was possible to appreciate, for each one of the various characteristics of the pedagogic practice, the extent to which the values of classification and framing of each teacher's practice were similar to or different from the value of classification and framing they indicated in the interview. Although in this study, the two components (ideas and practices) of teacher performance were analysed within the same conceptual framework, teacher performance was not conceptualized in terms of specific coding orientation. Thus, the data about the characterization of the practice were not transformed into degrees of active realization and the ideas shown in the interviews were not analysed in terms of recognition and passive realization.

The analysis of teacher performance and professional development in terms of the concept of specific coding orientation was initiated in a study, carried out by the ESSA Group, which focused on the relation between distinct modalities of pedagogic practice and the learning of a specific regulative text by primary school children (Rocha and Morais, 2000). This study involved teacher training within an action-research framework and was intended to encourage teachers to implement, at the level of classroom regulative context, a modality of pedagogic practice with successful characteristics (see Tables 9.1 and 9.2). Since this modality of practice was taken as the legitimate text to be produced by teachers, different levels of performance in relation to that text were taken as different levels of specific coding orientation to the context under analysis (see instruments of analysis). The data about active realization were obtained through an instrument (see instruments of analysis) constructed to characterize teacher performance in

Table 9.1 Characteristics of a mixed pedagogic practice: instructional context

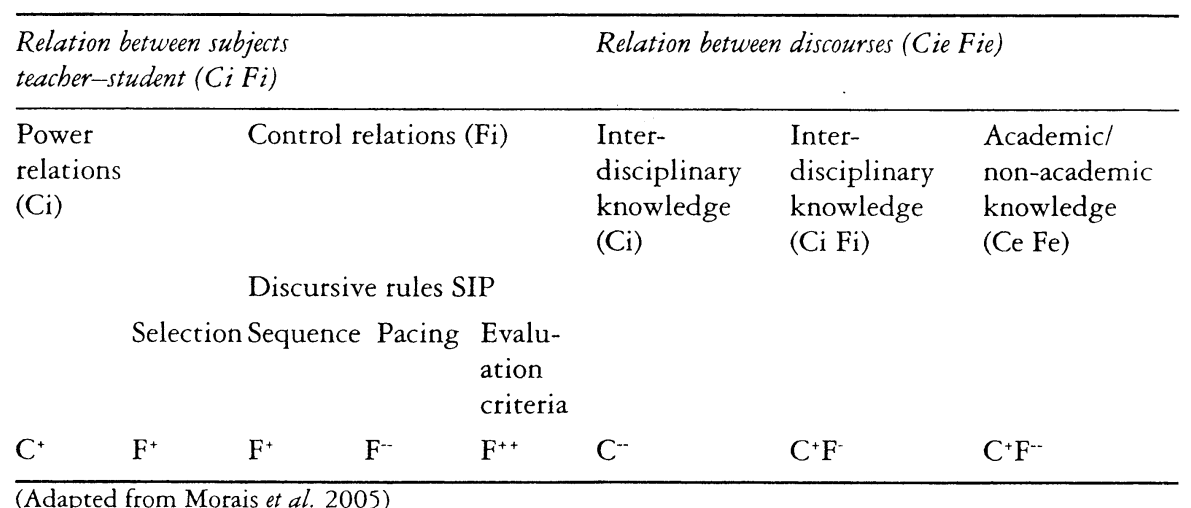


150 Ana M. Morais and Isabel P. Neves

Table 9.2 Characteristics of a mixed pedagogic practice: regulative context

\begin{tabular}{|c|c|c|c|c|c|}
\hline \multicolumn{2}{|c|}{ Relation between subjects (CiFi) } & \multicolumn{4}{|c|}{ Relation between spaces ( $C i)$} \\
\hline \multicolumn{2}{|c|}{ Teacher-student } & \multicolumn{4}{|c|}{ Student-student } \\
\hline \multirow[t]{2}{*}{$\begin{array}{l}\text { Power } \\
\text { relations }(\mathrm{Ci})\end{array}$} & $\begin{array}{l}\text { Control } \\
\text { relations }(\mathrm{Fi})\end{array}$ & $\begin{array}{l}\text { Power } \\
\text { relations }(\mathrm{C} i)\end{array}$ & $\begin{array}{l}\text { Control } \\
\text { relations }(\mathrm{Fi})\end{array}$ & $\begin{array}{l}\text { Teacher- } \\
\text { student space }\end{array}$ & $\begin{array}{l}\text { Student- } \\
\text { student space }\end{array}$ \\
\hline & $\begin{array}{l}\text { Hierarchical } \\
\text { rules }\end{array}$ & & $\begin{array}{l}\text { Hierarchical } \\
\text { rules }\end{array}$ & & \\
\hline $\mathrm{C}^{+}$ & $\mathrm{F}^{--}$ & $\mathrm{C}^{--}$ & $\mathrm{F}^{++}$ & $\mathrm{C}^{-}$ & $\mathrm{C}^{--}$ \\
\hline
\end{tabular}

the classroom in terms of the various characteristics of the pedagogic practice. The data about recognition and passive realization were obtained through discussions during the training process, without the direction of a specific instrument.

This study constituted the starting point for the construction of the initial instruments designed to analyse recognition and passive realization rules, in order to discriminate the various components of the specific coding orientation. The aim was to make it possible to understand the meaning of the various teacher levels of performance and their interrelation. It is possible that different levels of teacher performance may represent not only differences in the range of social relations of the pedagogic practice in which the teacher possesses the coding orientation, but also differences in the degree of coding orientation with respect to each one of the sociological characteristics used to define the pedagogic practice.

Let us begin with the modality of pedagogic practice that studies carried out by the ESSA Group have shown to be favourable to the learning of all students (e.g. Morais and Neves, 2001; Morais et al. 2004). This modality of practice, implemented by teachers as a result of their training process, was a mixed pedagogic practice - that is a practice with strong or weak classifications and framings according to specific aspects of the teaching-learning context (Rocha and Morais, 2000; Rosa 2002; Morais et al. 2005). Tables 9.1 and 9.2 show the characteristics of this modality of mixed pedagogic practice, in both instructional and regulative dimensions, where the scale of classification and framing is referred to four degrees $\left(\mathrm{C}^{++}, \mathrm{C}^{+}, \mathrm{C}^{-}, \mathrm{C}^{--} ; \mathrm{F}^{++}, \mathrm{F}^{+}, \mathrm{F}^{-}, \mathrm{F}^{--}\right)$.

In the context of this modality of mixed pedagogic practice, let us consider teacher performance when analysed in terms of specific coding orientation with reference, for example, to selection (see Table 9.1). According to this modality of pedagogic practice, selection should be characterized by a strong framing $\left(\mathrm{F}^{+}\right)$, that is the teacher should have control over the macro selection but $\mathrm{s} / \mathrm{he}$ should also give the students some control over the micro selection. If the teacher recognizes that this characteristic is to be valued in his/her pedagogic practice, s/he demonstrates possession of the recognition rules for selection in the teacher-student relation. If the teacher is also able to tell what should be done to meet that characteristic and to explicate the 
foundational principles underlying the selection of that characteristic, s/he also demonstrates passive realization for the same characteristic. If, when acting in the classroom, the teacher implements a pedagogic practice where this characteristic is present, s/he can also demonstrate active realization for that characteristic.

\section{Instruments of analysis}

This section starts by presenting some general aspects of instrument construction, followed by specific aspects referring to recognition and (active and passive) realization rules.

\section{General aspects}

As a result of the constructive methodology used in this study, which is based on the dialectical relation between the theoretical and the empirical, we have developed an external language of description for the analysis of teacher performance and professional development where the concept of specific coding orientation, that is part of the internal language of description, was the theoretical reference, and the 'texts' produced by teachers in both interview situations and classroom contexts were the main empirical data. The construction of the instruments started with the definition of indicators which, in empirical terms, would correspond to the various components of the specific coding orientation, that is to the recognition and (active and passive) realization rules, and to indicators which would be used to characterize the various social relations of the instructional and regulative contexts of a given pedagogic practice.

In order to co-ordinate, at both the conceptual and the empirical levels, the various components of specific coding orientation (recognition rules and active and passive realization rules), we needed to start by defining the social relations which would be the object of the analysis of teacher performance. These are relations which are part of instruments constructed for various studies (e.g. Morais and Neves, 2001) with the aim of characterizing the pedagogic practices implemented by teachers at various levels of schooling (see these relations in Tables 9.1 and 9.2). The instruments contained, for each relation, a set of empirical indicators ${ }^{1}$ and, for each indicator, descriptors corresponding to degrees indicated on a classification and/or framing scale. Thus, the sociological relations and the concepts of classification and framing we used to characterize teachers' pedagogic practice in the classroom context (and which gave us the performance in terms of active realization) were also used to evaluate the possession of recognition and passive realization to the context under study.

\section{Recognition and passive realization rules}

Data about recognition and passive realization have been obtained through semi-structured interviews with primary school and kindergarten teachers 


\section{Ana M. Morais and Isabel P. Neves}

within various action-research projects (Rosa, 2002; Morais et al. 2005). Both models of interviews, conducted so far, were structured around a series of questions, each of which centred on one of the social relations which define the instructional and regulative contexts of any modality of pedagogic practice. For each one of the relations, situations were given which illustrated modalities of practice with distinct characteristics. Teachers were asked to indicate a situation or situations which they would value (recognition) and to justify their choice (passive realization).

It is important to notice that, in these studies, our appreciation of passive realization was limited to the reasons teachers gave for privileging specific characteristics. The other dimension of passive realization, i.e. what should be done to meet those characteristics (Figure 9.2), was not considered in these analyses.

Although the two types of interview followed the same conceptual pattern, there were differences in their structures. In one type, the alternative is expressed in just one sentence and in the other it is expressed under the form of two hypothetical situations of pedagogic intervention. Below, we illustrate the two types of interview for the discursive rule selection:

\section{Interview 1}

What should teacher-children relations be like within the classroom?

Do you think that children should help to choose the content to be studied and the materials to be used?

Or do you think that it is the teacher who should select the content and materials? Why?

\section{Interview 2}

Imagine the following two situations related to the teaching-learning process in the classroom:

Situation $A$ - Activities related to living things, namely to animals, are taking place. In the course of the talk between two children a problem arises - 'Are plants living things or not?' Children ask the teacher who did not give an immediate answer. The teacher thought that the problem should be discussed in the groups, this theme becoming scientific content to be studied by all children. On the following day, some children brought in materials which helped them study the subject. Teacher and children together decided to develop further activities related to plants. Situation B - The theme/project chosen by the teacher is related to animals. Children ask questions, some of them referring to birds. The teacher, who is concentrating on mammals, ignores the children's questions, telling them that this will be studied later. It is the teacher who chooses the activities related to animals and does not use materials brought by children into the classroom but only materials she has selected. She is the only person who manipulates the material.

Which of these situations would you value? Why? 
In these examples, there is an alternative between a situation where some control over selection is given to the child (second question in Interview 1 and Situation $A$ in Interview 2) and a situation where selection is controlled by the teacher alone (third question in Interview 1 and Situation B in Interview 2). Although, in either of the two cases, there is evidently a dichotomy between a set of characteristics representing very strong framing (teacher's control) and a set of characteristics representing very weak framing (child's control), the interview was conducted in such a way that the teacher's choice was not limited to that dichotomy, but could also combine characteristics of the two situations. For example, in this particular case of selection of curricular content, the answers could be of a kind that showed that the control might be exclusively centred on the teacher in some cases, but also centred on the child in some others. ${ }^{2}$

In order to analyse the possession of recognition and passive realization rules by teachers, we constructed instruments on the basis of the interview responses. Considering the dialectical relation between the concepts which guided the analysis and the empirical data obtained from the various answers, we defined the main categories ${ }^{3}$ to be included in these instruments.

Tables 9.3 and 9.4 show the instruments of analysis of recognition and passive realization rules respectively. Each instrument is followed by excerpts from the interviews which illustrate one characteristic of the pedagogic practice - bierarchical rules (teacher-children relation). It is important to note that the analysis of the answers takes as reference the characteristics of the practice to be implemented by teachers as a result of the training they received. The examples refer to a pedagogic practice defined by very weak

Table 9.3 Instrument for analysing recognition rules and examples of interview excerpts concerning hierarchical rules (teacher/children relation)

\begin{tabular}{llll}
\hline $\begin{array}{l}\text { Instrument of analysis - Recognition rules }(R C) \\
\text { Indicator }\end{array}$ & Does not bave $R C$ & May have $R C$ & Has $R C$ \\
\hline $\begin{array}{l}\text { Characteristics } \\
\text { of pedagogic } \\
\text { practice }\end{array}$ & $\begin{array}{l}\text { Characteristics } \\
\text { indicated are } \\
\text { different from/ } \\
\text { opposed to those of } \\
\text { the theoretical model }\end{array}$ & $\begin{array}{l}\text { Characteristics } \\
\text { indicated are } \\
\text { ambiguous/not } \\
\text { clear }\end{array}$ & $\begin{array}{l}\text { Characteristics } \\
\text { indicated are } \\
\text { similar to those } \\
\text { of the theoretical } \\
\text { model }\end{array}$ \\
\hline
\end{tabular}

Examples of excerpts of interviews - hierarchical rules (teacher/children):

Does not have $R C$ - Sometimes I listen to their [the children's] reasons, but my present children enjoy talk a lot and sometimes I have to tell them that we cannot talk too much and I get cross with them to make them shut up, and I tell them that we are wasting our time ... I am unable to make them understand that we should not have too much talk ...

May bave $R C$ - This situation did not occur.

Has $R C$ - For example, I had given them [the children] some work to do and the time had run out, and I would try to lead them to understand that the time had run out and that next time they should have to keep more quiet $[\ldots]$ because the time would run out and the work was not done.

(Adapted from Morais et al. 2005) 


\section{Ana M. Morais and Isabel P. Neves}

Table 9.4 Instrument for analysing passive realization rules and examples of interview excerpts concerning hierarchical rules (teacher/children relation)

\begin{tabular}{|c|c|c|c|}
\hline \multicolumn{4}{|c|}{ Instrument of analysis - Passive realization rules $(R L p)$} \\
\hline Indicator & Does not have $R L p$ & May have $R L p$ & Has $R L p$ \\
\hline $\begin{array}{l}\text { Reasons given } \\
\text { for pedagogic } \\
\text { practice } \\
\text { chosen }\end{array}$ & $\begin{array}{l}\text { Reasons given are } \\
\text { different from/ } \\
\text { opposed to those of } \\
\text { the theoretical model }\end{array}$ & $\begin{array}{l}\text { Reasons given are } \\
\text { ambiguous/not clear } \\
\text { or no reasons are } \\
\text { given }\end{array}$ & $\begin{array}{l}\text { Reasons given are } \\
\text { similar to those of } \\
\text { the theoretical model }\end{array}$ \\
\hline
\end{tabular}

Examples of excerpts of interviews - hierarchical rules (teacher/children):

Does not bave $R L p$ - The teacher did not give any justification [the teacher started by showing herself not to have recognition rules - see example for Does not bave $R C$ ].

May bave $R L p$ - The teacher did not give a justification for the characteristic she chose and which corresponded to the theoretical model.

Has $R L p$ - I think it is very important to call their [the children's] attention [...] that the work was not properly done, they will be at a loss when they leave primary school ${ }^{4}[\ldots]$ they are accustomed to keep things going without bothering with the time they are spending! This is not going to happen later on, therefore we have to call their attention so that they are prepared ... it's a way of getting the habit of doing things properly.

(Adapted from Morais et al. 2005)

framing at the level of the hierarchical rules in the teacher-child relation (see Table 9.2).

Both instruments were used to guide the analysis of the data obtained in either of the two models of interviews. However, some adjustments in the analysis were needed, as a consequence of the specificity of each study. For example, at the level of the primary school, we had a considerable amount of data from classroom observations. For that reason, we used the possession of active realization rules as one more category to indicate the possession of passive realization and recognition rules. Thus, whenever, for a given characteristic of the pedagogic practice, the interview data was not clear about the possession of recognition and/or passive realization but the teacher's practice in the classroom clearly showed the presence of that characteristic, we assumed that the teacher would not only possess an active realization rule, but also recognition and passive realization rules. This is a consequence of the fact that, theoretically, the possession of active realization assumes necessarily the possession of recognition and passive realization.

The analysis of the interviews in the kindergarten study was different in that data about active realization was obtained from more limited and less diversified classroom interventions. For that reason the possession of active realization was not used as an indicator of recognition and passive realization. Instead, the possession of passive realization was taken as an important indicator in deciding about the possession of active realization. Thus, we considered that the teacher would only possess active realization if, together with a practice in the classroom which had the sociological characteristics favourable to children's learning, she had demonstrated in the interview that 
she had passive realization for these characteristics. We considered that acting in the classroom according to the model proposed, but in ways that were inconsistent or even contradictory in relation to the justifications given in the interview to explain those actions, might not indicate the possession of active realization. We thought that this ambiguous situation did not offer any guarantee that the practice implemented was based on pedagogic principles internalized by teachers - that is, that the practice implemented corresponded to a consistent pedagogic intentionality.

However, it is possible to accept that the inconsistencies sometimes witnessed between the interview data and the data based on classroom observation are a consequence of the way in which the instrument of analysis of recognition and passive realization was constructed and applied. We believe that, for example, the way passive realization was analysed was incipient, centring on a somehow restrictive aspect of this component of the specific coding orientation. According to the theoretical model (Figure 9.1), to possess passive realization means to select the meanings relevant to the context. In our interviews, the meanings to be selected corresponded to pedagogic principles which grounded given characteristics of the practice for successful learning by all children. However, following the model of Figure 9.2, we should consider another level of passive realization, according to which the meanings to be selected may also correspond to forms of acting in the classroom.

Let us again take selection of curriculum content (see above) as a reference. If (as in the interviews) we take the principles in which the pedagogic practice is grounded as the indicator of passive realization, teachers' answers should, then, refer to features such as the importance of children's interest, motivation and involvement, and their participation in the choice of some aspects related to the learning process (micro selection), but not others such as choice of the themes to be studied, given that children do not yet have the knowledge to choose an option relevant to their learning needs. However, if the indicator is forms of acting in the classroom which bring about successful practice, then teachers' answers should refer to features such as the teacher selecting the themes and sub-themes and then allowing the children to put questions and raise problems, or letting the children participate in the selection of materials previously chosen by the teacher. We believe that this new mode of empirically analysing passive realization needs further thought so that it can be used to substitute for the previous one or complement it. These are two alternative ways of looking at the empirical manifestation of passive realization. They appear to us at this moment as complementary forms which can give the analysis of passive realization greater powers of discrimination which, in turn, can give rise to a more comprehensive theoretical conceptualization of passive realization.

Analysis of recognition also requires improvement. We believe that we need to use a more diversified number of situations in order that answers are not conditioned by dichotomies which, to a certain extent, may indicate the choice valued by the interviewer. Although the interview questions were 
intended to be only guidelines for dialogue, so that choice was not necessarily limited by the dichotomy contained in the situations, the application of these models by other researchers may put in question the objectives of the interview. On the other hand, we believe it would be important to try to devise interview situations where it was possible to conduct a better exploration of the relation between possession/absence of recognition and passive realization rules. For example, in the models previously constructed, the absence of recognition appears associated with the absence of passive realization. As it stands, situations may occur where there is recognition and not passive realization, but there is no possibility of a situation where there is no recognition but there is passive realization (one of the indicators of the absence of passive realization is the absence even of recognition). To avoid this, a moment should be created in the interview where, in the absence of recognition rules, these would be given to the teacher. This procedure was part of interviews conducted with children to appreciate their specific coding orientation (e.g. Câmara and Morais, 1998) and which has given to the analysis of children's performance a greater explanatory power of differences encountered.

\section{Active realization rules}

The instruments employed to analyse active realization rules are the instruments we have used to characterize pedagogic practice in the classroom. These instruments have been subjected to successive reformulations and adaptations in order to achieve a higher level of significance of indicators and the empirical relations that define the contexts under study. We have sought a fine and rigorous analysis of teacher performance in the classroom and their professional development and, for this reason, we have been concerned with the selection of indicators that can cover a diversity of situations of that performance and with the specification of those situations through descriptors containing increasing powers of explication and discrimination.

As indicated above, the instruments used to characterize the pedagogic practice consider various social relations that define the instructional and regulative dimensions of teaching-learning contexts. The instruments contain a set of indicators applicable to each one of those relations and they contain the descriptors for each indicator which correspond to various degrees on the classification and/or framing scale.

Although following a similar pattern, the instruments may differ in the indicators selected for each one of the sociological characteristics under analysis and in the classification and framing scales. These differences are a function of the specificity of the contexts under study, the depth of the analysis and the scope of the research.

The indicators correspond to real situations in the pedagogic contexts under analysis, that is they are defined on the basis of situations previously observed in the classroom and which were found to be the most representative of what happens in those contexts. Thus, for example, 'Planning/doing 
experimental work' and 'Observing/interpreting and concluding in experimental work' are indicators only used in contexts of scientific learning where experimental work occurs and 'Presenting team work' is an indicator that is only relevant when students work in groups. The degrees of classification and framing represent, in any instrument, relative and not absolute values each degree referring to a given form of teacher action in the classroom.

As in the case of recognition and passive realization rules, the possession of active realization rules has been analysed in reference to each one of the social characteristics of the pedagogic practice. The observation of classroom activities and the transcription of tape and video recordings gave us the basis for analysing teacher performance, by taking as reference the 'type-behaviours' indicated in the instruments. For each one of the indicators of each sociological relation, the teacher's 'behaviour' is signalled, attributing to it one of the four degrees in the classification and framing scales. The 'behaviours' are registered on tables and the distribution of signals for the set of indicators of each characteristic of the pedagogic practice gives the trend of teacher action with reference to that characteristic. This procedure was completed by using the researchers' field notes. The final characteristic of teacher practice was a compound of both procedures.

Teacher performance, in terms of active realization, is evaluated with reference to the characteristics of the practice which are taken as the legitimate text of the pedagogic context under study. If we take as reference the modality of pedagogic practice that we have led teachers to implement in recent studies of our action-research projects (see Tables 9.1 and 9.2), to possess active realization means to create a performance in the classroom which has the characteristics of that practice.

For example, according to that practice, possession of active realization for the evaluation criteria would be shown by a very strong framing $\left(\mathrm{F}^{++}\right)$and for pacing and hierarchical rules (teacher-student) by a very weak framing $\left(\mathrm{F}^{--}\right)$. For some other characteristics, like selection and sequence, the possession of active realization would be shown by a strong framing $\left(\mathrm{F}^{+}\right)$, as a result of a very strong framing at the macro level and very weak framing at the micro level.

In order to make clear how active realization was evaluated, we show in Table 9.5 an example of one indicator of the instrument we constructed for analysing teacher pedagogic practice with reference to hierarchical rules (teacher-children). This is followed by two examples of classroom interactions, one of which indicates the possession of active realization for the characteristic under analysis.

When defining the indicators to evaluate the possession of active realization, we have recently considered new criteria. In order to discriminate between the macro and the micro levels of analysis, we have grouped indicators into two categories. These criteria were first used in the case of discursive rule selection to lead to the differentiation between macro selection and micro selection and are now being applied to the various characteristics of pedagogic practice (Silva et al. 2003). This distinction is related to the fact that some indicators are more associated with the general aspects of syllabuses whereas 


\section{Ana M. Morais and Isabel P. Neves}

Table 9.5 Extract of the instrument for analysing active realization rules and examples of transcripts concerning hierarchical rules (teacher/children relation)

\begin{tabular}{|c|c|c|c|c|}
\hline Indicator & $\mathrm{F}^{++}$ & $\mathrm{F}^{+}$ & $\mathrm{F}^{-}$ & $\mathrm{F}^{-}$ \\
\hline $\begin{array}{l}\text { when } \\
\text { addressing } \\
\text { cbildren }\end{array}$ & $\begin{array}{l}\text { The teacher does } \\
\text { not give any } \\
\text { reason, using the } \\
\text { imperative control }\end{array}$ & $\begin{array}{l}\text { The teacher uses } \\
\text { positional control, } \\
\text { giving reasons } \\
\text { related to school/ } \\
\text { classroom rules }\end{array}$ & $\begin{array}{l}\text { The teacher uses } \\
\text { personal control, } \\
\text { appealing to her } \\
\text { own reasons }\end{array}$ & $\begin{array}{l}\text { The teacher uses } \\
\text { personal control, } \\
\text { appealing to } \\
\text { children's personal } \\
\text { attributes }\end{array}$ \\
\hline
\end{tabular}

Examples of transcripts:

$\mathrm{Fi}^{++}$Cbild - Teacher, may I drink some water?

Teacher - Talk less and you won't need to drink so much - Does not bave RLa

$\mathrm{Fi}^{-}$Teacher - $[\ldots]$ respect for others so that nobody is disturbed [...] and now you are going to look at your worksheet, do what is indicated [...] cooperating with each other, waiting for your turn, right? And, keeping your voice down, for the group only, right. - Has RLa

(Adapted from Morais et al. 2005)

others are more related to specific aspects of pedagogic relations. For example, in the case of the indicators of the discursive rule selection, 'Themes/scientific contents' is an indicator of the macro level whereas 'Answers to children's questions/comments' is an indicator of the micro level. Grouping indicators in these two categories accords more rigour to the analysis of active realization and, in future, will also accord more rigour to the construction of instruments of analysis of recognition and passive realization.

The fact that teacher performance is viewed as a consequence of their specific coding orientation for a given context of the pedagogic practice means that distinct levels of performance correspond to distinct levels of specific coding orientation. Figure 9.3 shows schematically the empirical relation

\begin{tabular}{|c|c|c|}
\hline $\begin{array}{l}\text { Does not have } \\
\text { recognition rules }\end{array}$ & $\begin{array}{c}\text { Does not have } \\
\text { passive realization } \\
\text { rules }\end{array}$ & $\begin{array}{c}\text { Does not have active } \\
\text { realization rules (1) }\end{array}$ \\
\hline
\end{tabular}

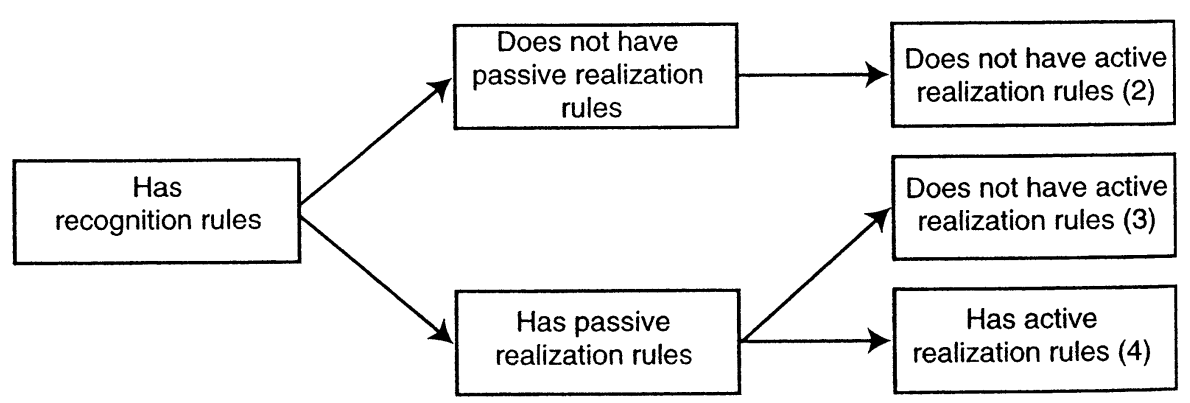

Figure 9.3 Levels of teachers' specific coding orientation 
which was made between recognition, passive realization and active realization rules, in order to give to each one of the characteristics of the pedagogic practice implemented by the teacher, different levels of specific coding orientation $(1,2,3,4)$ and therefore different levels of performance.

The transcripts that follow exemplify the level of coding orientation (level 3 ) which turned out to be the most frequent in a study carried out at the primary school level (Morais et al. 2005) when we looked at teacher performance with regard to the relations between discourses (intra-disciplinary, inter-disciplinary, academic/non-academic knowledges). The transcripts are part of the interviews and classroom observation.

\section{Intra-disciplinary relations}

What teacher Dulce tells us she does and why she does it [Interview responses]:

'[The scientific contents] are studied in an interlinked way' - HAS RECOGNITION.

'Because we cannot put them [the scientific contents] in separate compartments and that relation favours learning and makes it useful' - HAS PASSIVE REALIZATION.

What teacher Dulce does [Classroom observation]:

The teacher asks children for examples of state of matter changes which occur in the outside world. One of the children observes that when one places sea water under the sun, we will obtain salt instead of water. The teacher analyses the child's example in terms of state of matter changes and says that: 'The salt was dissolved in the water', but she does not indicate any relationship between this issue and the study of the dissolution of substances - DOES NOT HAVE ACTIVE REALIZATION.

\section{Inter-disciplinary relations}

What teacher Céu says she does and why she does it [Interview responses]:

'I relate science subjects to other subjects' - HAS RECOGNITION.

'Because in this way I can lead the child to develop a broader reasoning and that certain children can more easily apply the knowledge acquired in sciences to other areas and vic.e-versa' - HAS PASSIVE REALIZATION.

What Teacher Céu does [Classroom observation]:

Together with children, the teacher discusses the results obtained through the evaporation of alcohol and acetone. When comparing the initial and 
final levels of those liquids, some children observe that the level of the alcohol lowered $1 \mathrm{~mm}$. A child asks: Is it millimetre or millilitre [that should be written to indicate the lowering of the level of a substance]?

'He wrote millimetre. He wrote an $m$ and not an $l$, said the teacher. Children and teacher continue to discuss what happens to the alcohol and acetone without any reference to unities of length/volume, which is the content of Maths - DOES NOT HAVE ACTIVE REALIZATION.

\section{Academic-non academic knowledge}

What teacher Rita says she does and why she does it [Interviews' responses]:

'Yes, yes [I relate scientific knowledge to everyday knowledge]' - HAS RECOGNITION.

'[Because] it helps them to understand better the subject they are learning and helps them to understand what surrounds them ... those things they sometimes do not understand and that they can be helped to understand with the knowledge we give to them [...] it is easier to understand' - HAS PASSIVE REALIZATION.

What teacher Rita does [Classroom observation]:

Children were studying air constituents, that 'air' is different from 'oxygen' and that oxygen is used up in given phenomena, for example combustion. A child says that when she is in the classroom or in the car, 'she also feels without air' and 'she must fully open the car window'. The teacher listens to the child but does not explore her intervention in terms of what they had been studying in sciences, and she goes on by giving a new worksheet - DOES NOT HAVE ACTIVE REALIZATION.

One further significant aspect that should be considered in the analysis of teacher performance and professional development is the possession of socioaffective dispositions favourable to the pedagogic practice to be implemented (Figure 9.1). In the studies done so far, we have explored this, but not with the depth it deserves. The absence of socio-affective dispositions favourable to that characteristic may constitute a limiting factor in teacher performance. Future studies should explore combinations between specific coding orientation and socio-affective dispositions.

\section{Conclusion}

Productive discussion of new approaches to teacher professional development implies careful and sound evaluations, based on instruments that can be applied to the various contexts of initial and in-service teacher training and to various contexts of pedagogic intervention, in distinct levels of schooling. 
The main purpose of this chapter was to reflect on new paths for researching and analysing teacher performance by explaining what we have been doing and what we intend to do.

The analysis of teachers' professional development requires that what is going to be analysed is made clear and that appropriate instruments to be used for that analysis are constructed. In the research we have carried out, we structured and applied interview guidelines and instruments to characterize teachers' practices in order to analyse teacher performance in terms of specific coding orientation.

The level of depth and conceptual power of the model of analysis of teacher performance in terms of the specific coding orientation offers the possibility of making fine and detailed analyses of that performance and as such gives a better understanding of teacher difficulties in implementing pedagogic practices which have the potential to be successful. This is a crucial aspect for teacher training as it permits us to know with greater precision which are the components of teacher performance that teachers experience greater difficulties with. For example, it has been possible to distinguish teachers' difficulties at the level of their ideas/representations about the practices when discriminating between those ideas in terms of their possession of recognition and passive realization. It has also been possible to distinguish teacher difficulties at the level of their practices in the classroom by distinguishing between those practices in terms of the instructional and regulative contexts and within these in terms of various levels and various indicators of each one of the social characteristics of the pedagogic practice.

It would be possible, in the future, to accord a higher degree of accuracy to the analyses we have conducted. Although the structure of our interviews was organized to make possible the articulation of data about recognition and passive realization rules with data related to active realization rules, that articulation needs to be worked out more fully. We believe that a strong aspect of that structure is the fact that the interviews contained questions directed to each one of the social relations which have been the object of analysis when characterizing pedagogic practice in the classroom. This is an aspect which gives consistency to the analysis of the specific coding orientation, in terms of its various components. However, whereas for recognition and passive realization the analysis has been directed to the whole of each one of the relations, the analysis of active realization has considered each one of the indicators which together define each relation under analysis. In order that the analysis of teacher performance in terms of specific coding orientation increases in consistency and explanatory power, it is important that future instruments of analysis of recognition and passive realization include questions that give more precision to the evaluation of teachers' ideas/representations, with reference to the set of indicators selected for the analysis of each one of the sociological characteristics of the pedagogic practice. It is also important to distinguish, at the level of passive realization, two levels of ideas - the foundational principles which 
justify the valuing of given characteristics of the practice and the ways of acting to meet those characteristics.

We consider that the procedures we have followed to analyse teachers' professional development make a contribution to this field. We analyse this development in terms of the acquisition by teachers of recognition and realization rules and, in doing so, the studies suggest a methodological approach which gives the possibility of discriminating between specific components of teacher performance. However, in contrast with student learning where we have already conducted various studies leading to greater rigour of the instruments of analysis, the studies of the same kind at the level of teacher learning represent only a first step. We believe that considerable investment is needed in this area.

\section{Notes}

1 The following are examples of indicators for the discursive rule selection which were used in studies carried out in the science primary school contexts (Morais et al. 1997): exploring/discussing themes under study; doing activities; selecting materials; using models/schemes; planning/doing experimental work; using children's spontaneous selections; observing, interpreting and concluding in experimental work; answering children's questions; presenting group work; looking for information in books/journals/newspapers; finishing and recapitulating themes.

2 Answers of this kind would be in accordance with research results about the characteristics most favourable to children's learning which suggest that selection should be regulated by strong framing as a result of very strong framing at the level of the macro selection and weak framing at the level of the micro selection.

3 The whole system of categories used to evaluate teachers' possession/absence of the recognition rules and of the passive realization rules can be seen in Morais et al. 2005.

4 In Portugal, children leave primary school when they are ten years old and they enter elementary school, distinct in every aspect from primary school.

\section{Acknowledgements}

The authors acknowledge the financial support given to this study by the Foundation for Science and Technology, the Gulbenkian Foundation and the Institute for Educational Innovation.

\section{ERRATUM}

p. 149 - Table 9.1: Intra-disciplinary and not inter-disciplinary, in the 1st column under "Relation between discourses"

p. 150 - Table 9.2: $\mathrm{F}^{-}$and not $\mathrm{F}^{++}$, in the 4 th column 


\section{REFERENCES}

Bernstein, B. (1990). Class, codes and control, Vol. IV: The structuring of pedagogic discourse. London: Routledge.

Driel, J., Beijaard, D., \& Verloop, N. (2001). Professional development and reform in science education role of teachers' practical knowledge. Journal of Research in Science Teaching, 38 (2), 137-158

Matos, M., \& Morais, A. M. (2004). Trabalho experimental na aula de ciências física-químicas do $3^{\circ}$ ciclo do ensino básico: Teorias e práticas dos professores. Revista de Educação, XII (2), 75-93.

Morais, A. M., Neves, I. P., Afonso, A. \& Pires, D. (1997). Caracterização da prática pedagógica do $1^{\circ}$ Ciclo do Ensino Básico (Contexto instrucional e contexto regulador). ESSA Group, Department of Education, School of Science University of Lisbon.

Morais, A., \& Neves, I. (2001). Pedagogic social contexts: Studies for a sociology of learning. In A. Morais, I. Neves, B. Davies \& H. Daniels (Eds.), Towards a sociology of pedagogy: The contribution of Basil Bernstein to research (Chap. 8). New York: Peter Lang.

Morais, A., Neves, I., \& Afonso, M. (2005). Teacher training processes and teachers' competence: A sociological study in the primary school. Teaching and Teacher Education, 21, 415-437.

Morais, A., Neves, I., \& Pires, D. (2004). The what and the how of teaching and learning: Going deeper into sociological analysis and intervention. In J. Muller, B. Davies \& A. Morais (Eds.), Reading Bernstein, researching Bernstein (Chap. 6). London: Routledge \& Falmer.

Rocha, M. C., \& Morais, A. M. (2000). A relação investigador-professor nos projectos de investigação-aç̧ão Uma abordagem sociológica. In A. M. Morais, I. Neves et al, Estudos para uma sociologia da aprendizagem (Chap. XVII). Lisbon: Institute for Educational Innovation and Centre for Educational Research (SSUL).

Rosa, C. (2002). Actividades em ciências no jardim de infância: Estudo sobre o desenvolvimento profissional dos educadores. Master's Dissertation, School of Science University of Lisbon. (unpublished).

Silva, P., Morais, A. M., \& Neves, I. P. (2003). Caracterização da prática pedagógica do $1^{\circ}$ Ciclo do Ensino Básico (Contexto instrucional e contexto regulador). ESSA Group, Department of Education, School of Science University of Lisbon.

Wilson, S., \& Berne, J. (1999). Teaching learning and the acquisition of professional knowledge: An examination of research on contemporary professional development. In A. Iran-Nejad \& P. Pearson (Eds.), Review of Research in Education (Chap. 6). Washington: American Educational Research Association. 